\title{
INFLUENCE OF HEMOLYSIS ON ROUTINE CLINICAL CHEMISTRY TESTING
}

\author{
Mahmudul Haque ${ }^{1}$ Nazibun Nahar $^{2}$ Md Tipu Sultan ${ }^{3}$ Rehana Aziz ${ }^{4}$ Sirajul Islam ${ }^{5}$ M A Mazed ${ }^{6}$
}

\begin{abstract}
While analytical standards have been developed by established quality control criteria, there has been paucity in the development of standards for the preanalytical phase ${ }^{1.4}$. Every laboratory should have a strategy for recognizing preanalytical errors. In this study there was a consistent trend towards overestimation of creatinine, Creatine kinase and potassium but glucose in the analytes was decreased significantly.
\end{abstract}

\section{Introduction}

Preanalytical factors are the main source of variation in clinical chemistry testing and among the major determinants of Preanalytical variability; sample hemolysis can exert a strong influence on result reliability ${ }^{2,3}$. Hemolytic samples are a rather common and unfavorable occurrence in laboratory practice, as they are often considered unsuitable for routine testing due to biological and analytical interference. However, definitive indications on the anaiytical and clinical management of hemolyzed specimens are currently lacking. Therefore, the present investigation evaluated the influence of in vitro blood cell lysis on routine clinical chemistry testing.

\section{Methods}

Five aligusts, prepared by serial dilutions of homologous hemolyzed samples collected from 12 different subjects and containing a final concentration of serum hemoglobin ranging from below 6.0, 6-10 more than $10 \mathrm{~g} / \mathrm{L}$, were tested for the most common clinical chemistry analytes. Lysis was achieved by subjecting whole blood to an overnight freeze-thaw cycle. From each of them Serum glucose, creatinine, creatine kinase and potassium were estimated. Results were presented in tables and graphs.

\footnotetext{
1. Professor of Biochemistry

2. Lecturer of Physiology

3. Assistant Professor of Virology

4. Assistant Professor of Biochemistry

5. Assistant Professor of Biochemistry

6. Assistant Professor of Microbiology

Chittagong Medical College, Chittagong

Correspondence: Dr Mahminulul Haqué
}

\begin{abstract}
Results
Hemolysis interference appeared to be almost approximately . linearly dependent: on the final concentration of blood-cell lysate in the specimen. This generated a consistent trend towards overestimation of creatinine (Table-I, Graph-1) creatine kinase (CK) (Table-II, Graph-2) and potassium (Table-III, Graph-3) whereas mean value of glucose were substantially decreased (Table-IV, Graph-4)
\end{abstract}

\section{Discussion}

Only recently recommendations have been published regarding the quality of samples including the definition of the optimal sample size, the use of anticoagulants and stabilizers, stability criteria regarding transport and storage and handling of hemolytic, lipemic and icteric samples ${ }^{5,7}$.

Hemolysis may interfere with chemistry tests by the following mechanisms:

1. Increased absorbance Released hemoglobin increases absorbance in the spectral range $e^{2,3}$.

2. Inhibition of reactions: Released hemoglobin can directly inhibit chenical reactions.

3. Analytes release: Release of analytes found in high concentrations in red blood cells will falsely elevating the values of these analytes.

4. Enzyme release: Release of enzymes which participate in chemical reactions, e.g. Creatine kinase 4 .

5. Water release: Release of red blood cell water dilutes analytes ${ }^{8}$.

\section{Conclusion}

If hemolysis and blood cell lysis result from an in vitro cause, it may be suggested that the most convenient corrective solution might be quantification of free hemoglobin, alerting the clinicians and sample recollection. The rather heterogeneous and unpredictable response to hemolysis observed for several parameters prevented the adoption of reliable statistic corrective measures for results on the basis of the degree of hemolysis.

\section{Recommendation}

Though recommendations have been documented regarding the quality of samples including hemolysis, 9 but establishment of a quality manual addressing preanalytical variables is a prerequisite 
for implementing measures to recognize and control this crucial component of laboratory quality, which cannot be detected by traditional analytical quality control procedures. From this study it may be suggested a standard operating procedure must be prepared during blood sample collection to prevent hemolysis.

Graph-1: Creatinine in analytes in $\mathrm{mg} / \mathrm{dl}$

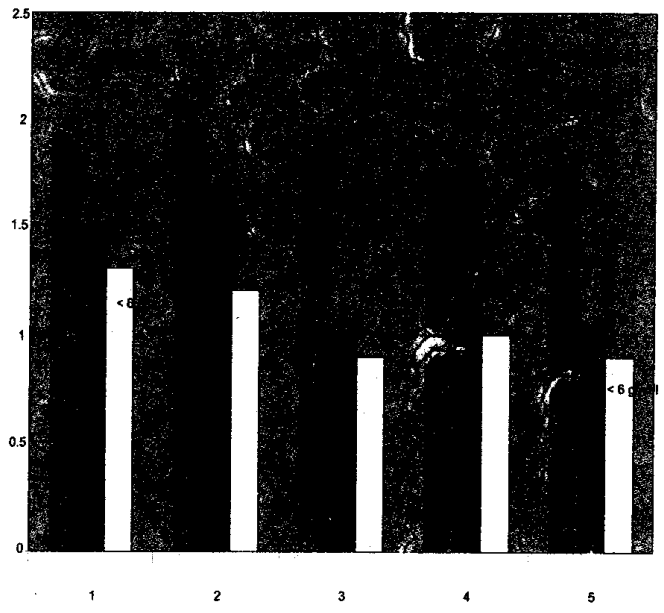

Graph-2: Change in creatine kinase in $\mathrm{U} / \mathrm{L}$

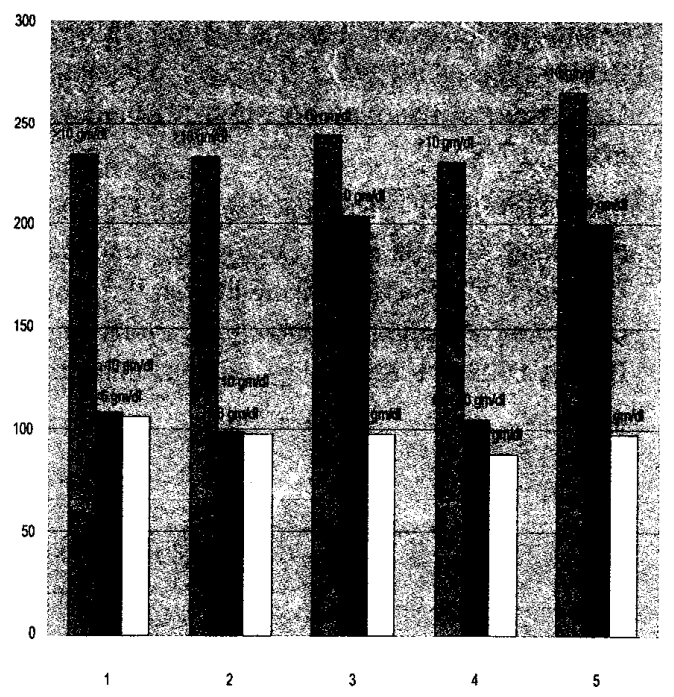

Graph-3: Potassium in MEQ/L

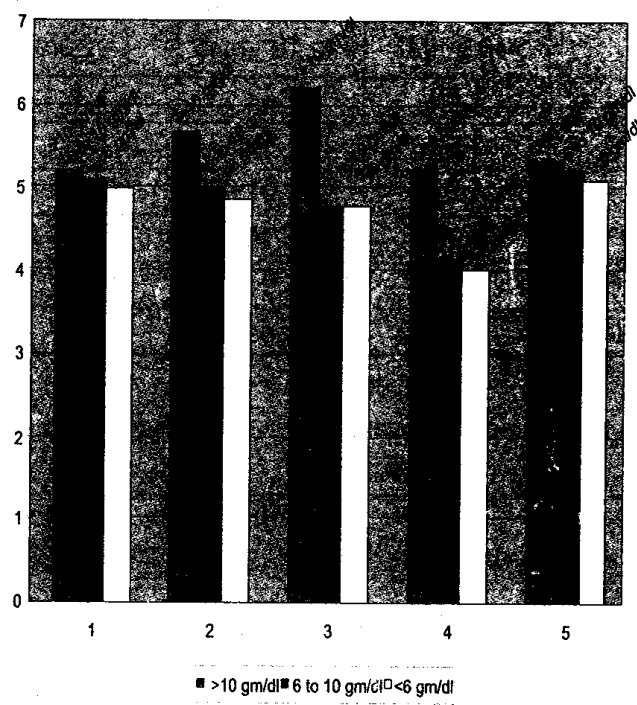

Graph-4: Change Of Glucose In Analytes

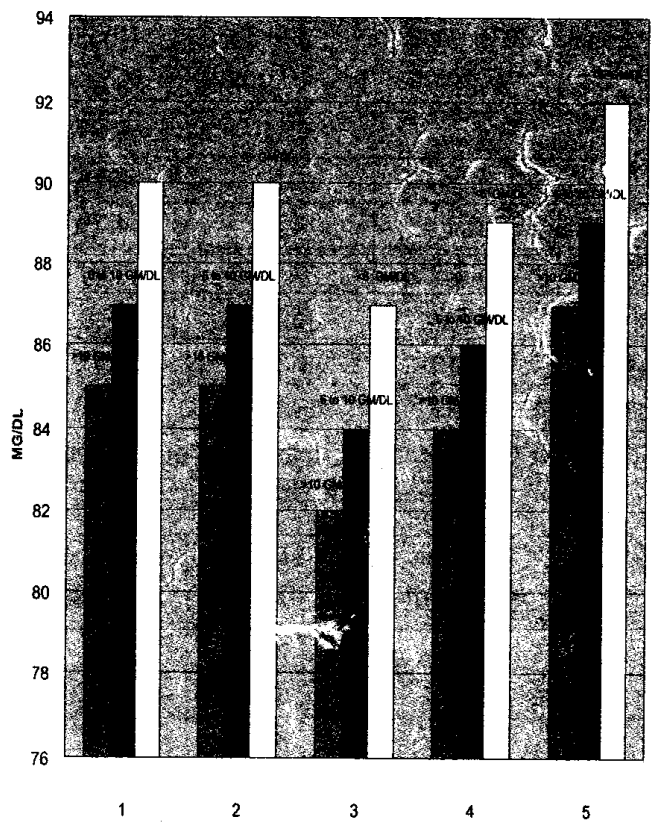


Table-I: Creatinine $\mathrm{mg} / \mathrm{dl}$ analytes in different concentration of $\mathrm{Hb}$

\begin{tabular}{|c|c|c|c|}
\hline Creatinine & $\begin{array}{r}\mathrm{Hb} \text { conc } \\
>10 \mathrm{gm} / \mathrm{dl}\end{array}$ & $\begin{array}{r}\mathrm{Hb} \text { conc } \\
6 \text { to } 10 \mathrm{gm} / \mathrm{dl}\end{array}$ & $\begin{array}{r}\mathrm{Hb} \text { conc } \\
<6 \mathrm{gm} / \mathrm{dl}\end{array}$ \\
\hline 1 & 1.89 & 1.42 & 1.3 \\
\hline 2 & 1.98 & 1.66 & 1.2 \\
\hline 3 & 1.92 & 1.01 & 0.89 \\
\hline 4 & 1.78 & 1.76 & 0.99 \\
\hline 5 & 1.88 & 1.01 & 0.89 \\
\hline Mean & 1.89 & 1.65 & 1.054 \\
\hline
\end{tabular}

Table-II: Creatine Kinase U/L in analytes in different concentration of $\mathrm{Hb}$

\begin{tabular}{|c|c|c|c|}
\hline $\begin{array}{l}\text { Creatine } \\
\text { Kinase }\end{array}$ & $\begin{array}{c}\mathrm{Hb} \text { conc } \\
>10 \mathrm{gm} / \mathrm{dl}\end{array}$ & $\begin{array}{r}\mathrm{Hb} \text { conc } \\
6 \text { to } 10 \mathrm{gm} / \mathrm{dl}\end{array}$ & $\begin{array}{c}\text { Hb conc } \\
<6 \mathrm{gm} / \mathrm{dl}\end{array}$ \\
\hline 1 & 234 & 108 & 106 \\
\hline 2 & 233 & 99 & 97 \\
\hline 3 & 244 & 204 & 97 \\
\hline 4 & 231 & 105 & 88 \\
\hline 5 & 265 & 201 & 97 \\
\hline Mean & 241.4 & 143.4 & 97 \\
\hline
\end{tabular}

Table-III: $\mathrm{K}^{+}$soncentration $\mathrm{Meq} / \mathrm{L}$ in analytes in different concentraiion of $\mathrm{Hb}$

\begin{tabular}{|c|c|c|c|}
\hline Fotassium & $\begin{array}{c}\mathrm{Hb} \text { conc } \\
>10 \mathrm{gm} / \mathrm{dl}\end{array}$ & $\begin{array}{r}\mathrm{Hb} \text { conc } \\
6 \text { to } 10 \mathrm{gm} / \mathrm{dl}\end{array}$ & $\begin{array}{c}\mathrm{Hb} \text { conc } \\
<6 \mathrm{gm} / \mathrm{dl}\end{array}$ \\
\hline 1 & 5.2 & $\vdots .1$ & 4.99 \\
\hline 2 & 5.66 & 5 & 4.86 \\
\hline 3 & 6.2 & 4.78 & 4.79 \\
\hline 4 & 5.22 & 4.15 & 4.01 \\
\hline 5 & 5.31 & 5.24 & 5.1 \\
\hline Mean & 5.518 & 4.854 & 4.75 \\
\hline
\end{tabular}

Table-IV: Glucose $\mathrm{mg} / \mathrm{dl}$ in analytes in different concentration of $\mathrm{Hb}$

\begin{tabular}{|c|c|c|c|}
\hline Glucose & $\begin{array}{c}\mathrm{Hb} \text { conc } \\
>10 \mathrm{gm} / \mathrm{dl}\end{array}$ & $\begin{array}{r}\mathrm{Hb} \text { conc } \\
6 \text { to } 10 \mathrm{gm} / \mathrm{dl}\end{array}$ & $\begin{array}{c}\text { Hb conc } \\
<6 \mathrm{gm} / \mathrm{dl}\end{array}$ \\
\hline 1 & 85 & 87 & 90 \\
\hline 2 & 85 & 87 & 90 \\
\hline 3 & 82 & 84 & 87 \\
\hline 4 & 84 & 86 & 89 \\
\hline 5 & 87 & 89 & 92 \\
\hline Mean & 84.6 & 86.6 & 89.6 \\
\hline
\end{tabular}

\section{References}

1. Narayanan S. The preanalytic phase - An important component of laboratory medicine. Am J Clin Pathol 2000; 113: 429-452

2. Guder, WG, Narayanan S, Wisser H, Zawta B. Samples from the patient to the laboratory. The impact of preanalytical variables on the or of laboratory results. Darmstadt, Germany: GIT Verlag, 1996

3. Young DS. Effects of preanalytical variables on clinical laboratory tests. Washington, DC: AACC Press, 2 nd ed, 1997

4. Guder, WG. Preanalytical factors and their influence on analytical quality specifications. Scand J Clin Lab Invest 1999; 59: 545-550

5. The Quality of Diagnostic Samples. Recommendations of the working group on preanalytical variables of the German Society for Clinical Chemistry and the German Society for Laboratory Medicine. Darmstadt, Germany: GIT, 2000.

6. Guder WG, Fonseca-Wollheim Fd, Heil W, Schmitt YM, Topfer G, Wisser $\mathrm{H}$, et al. The hemolytic, icteric and lipemic sample.

7. Recommendations regarding their recugnition and prevention of clinically relevant interferences. Lab Med 2000; 24: submitted.

8. DIN ISO 6710. Single use containers for venous blood specimen solection. Berlin: Beuth Verlag, 1996. NCCLS. Specimen Collection. Villanova, PA, USA: Document SC2-L, $1999^{\circ}$.

9. Inspection check- lists and commentaries for laboratory accreditation. College of American Pathologists Laboratory Accreditation Program. College of American Pathologists, Ncithfield, Illinois 60093. U.S.A. 21 st edition, Fe'Jruary 2000 . 